\title{
Indoor Vertical Farming Systems for Food Security and Resource Sustainability ${ }^{1}$
}

\author{
Jiangxiao Qiu, Haimanote K. Bayabil, and Yuncong $\mathrm{Li}^{2}$
}

\section{Abstract}

Addressing food security while satisfying sustainability needs remains one of the most significant challenges for human society in the $21^{\text {st }}$ century. Indoor vertical farming has been gaining increased popularity worldwide and is considered a revolutionary technology of producing food by almost completely excluding natural interferences (e.g., soil, sunlight, rainfall, and wind), hence termed as the "Third Green Revolution." This paper provides a comprehensive summary of the current status of indoor vertical farming in the United States and globally, commercial derivatives, major sustainability benefits (i.e., economic, environmental, and social), as well as limitations and challenges. We conclude that although there are substantial potential benefits from indoor farming both for food security and resource sustainability, more research is needed that carefully assesses and confirms these effects at different locations and scales. It is projected that future technological advancements and policy support will help foster the widespread adoption of indoor vertical farming that can complement existing rural farming approaches to address future sustainability challenges.

\section{Introduction}

We are now entering an era in which more than half of the global population is living in urban areas. It is projected that by 2050 , total population will rise to $\sim 10$ billion and urbanization will reach $68 \%$ of the total global population, which is equivalent to increases by almost one million every 10 days (Forman and Wu 2016). As the world's population skyrockets, there is no doubt that the demand for food and other critical resources (e.g., water and energy) will continue to soar (Seto et al. 2017; Acuto et al. 2018). It is estimated that the demand for food will increase by almost $70 \%$, causing food security challenges and putting pressure on the current food systems (Rosegrant and Cline 2003). Scarcity of freshwater resources will continue to be a major limiting factor for increased food production with conventional farming practices (Foley et al. 2011). Availability of farmlands will also become a main limitation around the world, with an increasing demand for urbanization and residential development to accommodate the needs of a booming population (Alig et al. 2004). Besides land scarcity, long-term land degradation is another factor that affects sustained food production. It is obvious that converting forest lands or wetlands will be undesirable because such land transformation will lead to deforestation, soil erosion, increased greenhouse gas (GHG) emission, and ultimately the losses of other essential ecosystem services (Qiu and Turner 2013, Qiu et al. 2018). Hence, to meet the world's future food security and resource demands, there is a compelling need to explore innovative farming solutions that allow the production of more food per land or water use while simultaneously minimizing its environmental footprints.

1. This document is FOR360, one of a series of the School of Forest Resources and Conservation, UF/IFAS Extension. Original publication date March 2020. Visit the EDIS website at https://edis.ifas.ufl.edu for the currently supported version of this publication.

2. Jiangxiao Qiu, assistant professor, School of Forest Resources and Conservation, UF/IFAS Fort Lauderdale Research and Education Center; Haimanote K. Bayabil, assistant professor, Department of Agricultural and Biological Engineering, UF/IFAS Tropical Research and Education Center; and Yuncong Li, professor, Department of Soil and Water Sciences, UF/IFAS Tropical Research and Education Center; UF/IFAS Extension, Gainesville, FL 32611.

The Institute of Food and Agricultural Sciences (IFAS) is an Equal Opportunity Institution authorized to provide research, educational information and other services

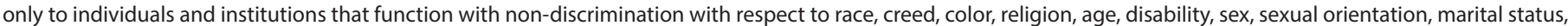

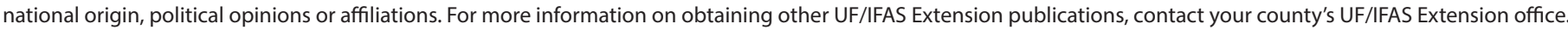
U.S. Department of Agriculture, UF/IFAS Extension Service, University of Florida, IFAS, Florida A \& M University Cooperative Extension Program, and Boards of County Commissioners Cooperating. Nick T. Place, dean for UF/IFAS Extension. 
The indoor farming industry (currently estimated at $\sim \$ 300$ billion), with the aids of technological advances, plays a pivotal role in increasing food production and achieving environmental sustainability. Indoor farming systems includes vertical farming, vegetable towers, hydroponics, aeroponics, modular container systems, and cubic production systems (Figure 1). Indoor farming systems maximize use of vertical space and adopt new techniques to achieve high water- and nutrient-use efficiencies, with higher yield per unit area (Benke and Tomkins 2017). Indoor farming is considered a revolutionary technology for producing food without natural interferences (e.g., soil, sunlight, rainfall, and wind) and has been termed as the "Third Green Revolution." Under conventional crop production systems in the field (e.g., row crops) or in greenhouses, crops are grown in a single layer to ensure adequate sunlight and reduce resource competition over the crop canopy as well as in the root zones. In contrast, in the indoor vertical farming system, crops are grown in multiple layers and are integrated into skyscrapers, warehouses, and shipping containers to obtain the maximum productivity per area of land use. The capacity to grow crops vertically is critical because it substantially reduces the baseline land requirements for agricultural production, and also the vertical farms can be implemented in locations with land constraints (e.g., urban centers) and under extreme environmental conditions (e.g., deserts) that are traditionally deemed unsuitable for food production.
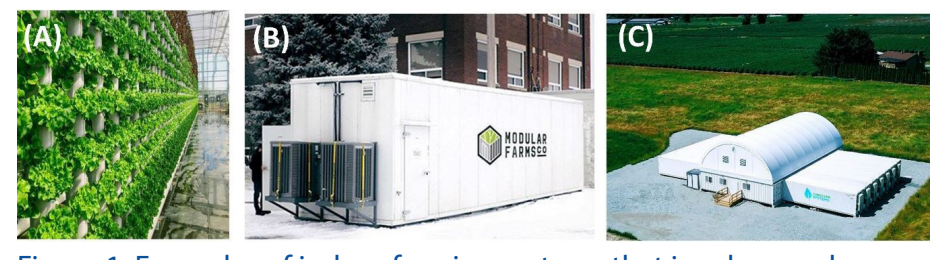

Figure 1. Examples of indoor farming systems that involve much greater use of technology and automation for land-use optimization so that crops are grown vertically in multiple layers and are integrated into skyscraper buildings or inside warehouses or shipping containers. (A) Hydroponics; (B) Modular container system (http:// www.modularfarms.com.au/); (C) Cubic production system (https:// cubicfarms.com/). Photos are used with permission.

\section{Sustainability Benefits of Indoor Vertical Farming}

There are a number of economic, environmental, social, and political advantages of indoor vertical farming that are appealing to policymakers and growers. Economic benefits include minimum requirements of inputs such as herbicides and pesticides and no need of soils if hydroponics or aeroponics are used as the growing method. In addition, large farming machinery such as tractors, trucks, and harvesters is not required for indoor farming. Because of the highly controlled environment, the production will be free of extreme-weather related stresses that can cause annual yield variability and significant quality and yield losses. The capacity of all-year-round production and no seasonality issues can help boost total yields and increase biomass per unit land area, leading to increased profits. Due to its small land requirement, an indoor farm can be located near consumers (e.g., in and near cities) to reduce costs associated with long-distance transportation. Moreover, indoor vertical farming can also be integrated with other technologies such as renewable energies (e.g., solar panels on the roof of the growing facility) to reduce the energy-use costs.

Environmentally, there are also substantial benefits. Prominent examples include the provision of sufficient and healthy organic food (i.e., food security) that is not contaminated by chemicals. However, in the United States the organic certification by the Department of Agriculture is only applicable to soil-based products. Indoor farms also have greater water-use efficiency, which reduces the need for freshwater withdrawal for irrigation. Specifically, indoor vertical farming is claimed to have up to $350 \%$ greater water efficiency, and uses as low as $1 \%$ of the water compared to conventional open field production systems (Nex 2018). Water-related benefits can also be enhanced through the recycling of gray water (e.g., from stormwater harvesting). Higher nutrient-use efficiency in a controlled and circular system allows for the minimization of nutrient losses, and reduces the contamination of freshwater resources (e.g., eutrophication). Other environmental benefits include reduction in energy consumption and greenhouse gas emissions from long-distance transportation of both food and farm inputs for crop production (e.g., fertilizer, pesticides). Because there is no disruption to the land (e.g., conventional tillage), the vertical farming can avoid carbon and nutrient losses and maintain the long-term health of soils. Because of its production in an indoor environment, there is essentially no air pollution associated with the production process (e.g., emissions from large machinery).

Socially, vertical farming provides benefits such as creation of jobs in sectors of engineering, biotechnology, construction, and research and development (Benke and Tomkins 2017). This is relevant because vertical farming can be implemented within or near urban areas to access a large labor pool. In addition, the capacity to locate farms in urban centers could also help rejuvenate neglected or less developed neighborhoods by using empty/abandoned buildings, vacant lots, and disused warehouses for production. This further helps to address issues related to income inequality and could potentially lead to crime reduction. 
The provision of healthy, fresh, and affordable food could also help address chronic diseases (e.g., diabetes, obesity, heart disease), especially in "food desert" regions (Savelle and O'Neal 2017). Moreover, indoor vertical farming systems, through the increased use of automation, can enhance workers' protection against injuries from using heavy field equipment and exposure to harmful chemicals. Further, vertical farming facilities, especially those in the business districts, have elements of collective enterprises, with social interactions. They can provide meeting avenues with opportunities for making new friendships and establishing partnerships.

There are also political benefits associated with indoor vertical farming that are worth discussing. One potential benefit is related to the commitments of GHG emission reduction to combat climate change (e.g., Paris Agreement), which can be achieved through technology-aided adaptation and mitigation. Another possible benefit is the reduction of water conflicts and downstream water pollution and contaminants, especially in areas with cross-border water flows.

\section{Current Status and Commercial Derivatives}

Indoor farming production has the potential to be programmed year round and on demand, regardless of the natural weather conditions, season, or annual climate variability. The artificial control of light, temperature, humidity, and nutrients makes crop production indoors not only possible but also extremely efficient because plant-growing conditions can be fine-tuned to the optimal ranges to support high yields at the shortest possible duration to produce the best quality of the product. By contrast, dependence on the natural environment leaves farms vulnerable to fluctuating, unreliable, and sometimes extreme conditions. Thanks to its many practical features, indoor vertical farming has been gaining popularity and has been widely adopted around the globe, including in the Antarctic and desert regions (e.g., Middle East, Africa), and in small, highly urbanized countries such as Israel and Japan. Indoor vertical farming is also attractive in countries without land constraints (e.g., the United States) because of its economic and environmental advantages and in countries that suffer from heavy pollution and soil depletion, such as parts of China.

Typical features and recent technological innovations related to indoor vertical farming include (1) lighting techniques, such as LED that offers precise control of light spectrum and intensity for critical vegetative and reproductive phases of crop development and that can be programmed for optimal photosynthesis for different types of crops; (2) automatic air- and humidity-control at specific levels that optimize the rate of plant growth; (3) solar panels for lighting and heating; (4) recycled water systems that augment with rainwater or water from a desalination plant. The use of aeroponics, aquaponics, and hydroponics enable balanced nutrition at each growth period to optimize the nutrient- and water-uptake efficiency by minimizing losses. This, in turn, reduces the need for fertilizers, herbicides, and pesticides. Any nutrients and water not absorbed by the roots can be recycled in the system. There are multiple claims that water use in vertical farming could be much less than that for traditional crops; in some claims, even as much as 95 percent less. Similar claims are made for nutrient-use efficiency. However, these water- and nutrient-use efficiency claims have not yet been consistently proven and need further confirmation by carefully planned experimentation and monitoring for proper comparisons. If the claims prove to be accurate, the water and nutrients it can save will render the promotion of vertical farming worthwhile, particularly in regions where resources are scarce.

Current predictions suggest that by 2024 the vertical farming market in the United States will be $\$ 3$ billion, which is an aggressive growth of about 24 percent annually from 2018 to 2024 (Cision 2019). Growth is being driven by the multiple benefits of the vertical farming system, as explained above, especially its capacity to support sustainable food security and high water-use efficiency. In the United States today, one of the largest commercial vertical farm facilities (70,000 square feet, 30 feet high) is in Newark, New Jersey, operated by AeroFarms (https://aerofarms. $\mathrm{com} /$ ). It is estimated to produce 2 million pounds of greens per year using aeroponics and have yields 390 times higher per square foot annually compared to traditional farming approaches. This company has eight other smaller facilities and plans to build another large 78,000-square-foot facility in Camden, NJ. Prominent technologies being incorporated in these operations include smart aeroponics (e.g., automation), light control, smart nutrient delivery, and pest management.

Pressure on arable land is much greater in Asian countries than in the United States. For example, Japan has heavily invested in commercial vertical farming with almost 200 facilities already operational. In China, currently there are 80 vertical farms, which are expanding at a faster rate. In Kranji, near Singapore's central business district, there are 
$\sim 120$ vegetable towers erected, and there are plans to build an additional 300 to support daily production of two tons of vegetables.

To date, indoor vertical farming technology has gained attention mostly in developed countries such as Japan, South Korea, the United States, and the United Kingdom. The only exception is China, where population pressure per unit of land is extremely high, and water scarcity is continuing to impact traditional farming. The big unknown for future large-scale adoption of this new technology is its affordability, particularly in the developing economies of the world, where food insecurity is severe and continues to get worse. Therefore, to make a dent in global food insecurity, we need technologies that are affordable, accessible, and adaptable for low-income countries. For now, vertical farming technology fails to satisfy these requirements. Like any new technology, we hope that the cost of vertical farming may come down with time. That could make this technology more appealing with increased adoptions on a wide scale.

\section{Current Limitations and Challenges}

Start-up costs are often barriers to the establishment of indoor vertical farming systems, especially in developing countries. Other constraints have to do with the limited range of crops suitable for this model, such as lettuce, tomato, pepper, and strawberries (Cox 2016). Staple crops, such as corn, soybean, and rice, at least with the current technology, are not ideal for indoor production. Another limitation is that current production volumes are not as large as those of large-scale farm operations, and scaling-up can be cost-prohibitive (Benke and Tomkins 2017). Finally, there are no pervasive incentive or policy initiatives that can facilitate the adoption of vertical indoor farming at the large scale necessary to meet the food demands of a growing population. Large-scale implementation of indoor farms also requires a skilled workforce that has yet to be developed.

\section{Conclusion}

Land area is precious in an urban setting; therefore, traditional farming is not convenient or environmentally feasible. To overcome these limitations, the new trend is to practice vertical farming either in high-rise buildings, insulated shipping containers, or modular systems that can be located in such places as parking lots or vacant lots. Fully automated turnkey operational containers can be installed on small pieces of land in urban areas for production of a variety of crops, including ornamentals, pharmaceuticals, nutritional supplements, flavors, etc. These vertical farming systems may present archetypes for future farming and can help achieve the three pillars of sustainability (i.e., environmental, economic, and social) as well as various United Nations Sustainable Development Goals (Griggs et al. 2013). Economic impacts include enhanced productivity with lower resource demands (land, water, nutrients, and other human inputs), reduced loss from natural disasters, decreased costs associated with food supply chains, and year-round production. Key environmental benefits include provision of healthy and affordable food, reduced carbon emissions and energy uses, minimized water pollution, and reduced impacts on soils. Social benefits include provision of employment, social interactions and cohesion, community building, personal wellbeing, and a sense of place. While these are the benefits described in the literature, more research is needed to further confirm these effects at different locations and across different scales. It is anticipated that future technological advancements and policy support will help foster the widespread adoption of indoor vertical farming that can complement existing rural farming approaches to address the sustainability challenges we are facing in the $21^{\text {st }}$ century.

\section{References}

Acuto, M., S. Parnell, and K. C. Seto. 2018. Building a Global Urban Science. Nature Sustainability 1:2-4.

Alig, R. J., J. D. Kline, and M. Lichtenstein. 2004. "Urbanization on the US landscape: Looking Ahead in the 21st Century." Landscape and Urban Planning 69:219-234.

Benke, K., and B. Tomkins. 2017. "Future food-Production Systems: Vertical Farming and Controlled-Environment Agriculture." Sustainability: Science, Practice and Policy 13:13-26.

Cision News. 2019. "United States $\$ 3$ Billion Vertical Farming Market to 2024: Growing Popularity of Plug \& Play Farms Scope for Automation Using Big Data and AI." Available at: https://www.prnewswire.com/news-releases/ united-states-3-billion-vertical-farming-market-to2024-growing-popularity-of-plug--play-farms--scope-forautomation-using-big-data-and-ai-300783042.html. Based on Report, "Vertical Farming Market in the U.S. - Industry Outlook and Forecast 2019-2024", by Research and Markets. 
Cox, S. 2016. "Enough with the Vertical Farming Fantasies: There are Still Too Many Unanswered Questions about the Trendy Practice." Available at: https://randevmat2017. wordpress.com/2017/06/27/enough-with-the-verticalfarming-fantasies-there-are-still-too-many-unansweredquestions-about-the-trendy-practice/

Foley, J. A., N. Ramankutty, K. A. Brauman, E. S. Cassidy, J. S. Gerber, M. Johnston, N. D. Mueller et al.. 2011. "Solutions for a Cultivated Planet." Nature 478:337-342.

Forman, R. T. T., and J. Wu. 2016. "Where to Put the Next Billion People." Nature 537:608-611.

Griggs, D., M. Stafford-Smith, O. Gaffney, J. Rockström, M. C. Öhman, P. Shyamsundar, W. Steffen, G. Glaser, N. Kanie, and I. Noble. 2013. "Policy: Sustainable Development Goals for People and Planet.” Nature 495:305-307.

Nex, S. 2018. "The 10 Biggest and Best Vertical Farms." Available at: https://www.maximumyield.com/ future-farming-the-biggest-and-best-vertical-farms/2/17389

Qiu, J., S. R. Carpenter, E. G. Booth, M. Motew, S. C. Zipper, C. J. Kucharik, X. Chen, S. P. Loheide, J. Seifert, and M. G. Turner. 2018. "Scenarios Reveal Pathways to Sustain Future Ecosystem Services in an Agricultural Landscape." Ecological Applications 28:119-134.

Qiu, J., and M. G. Turner. 2013. "Spatial Interactions among Ecosystem Services in an Urbanizing Agricultural Watershed." Proceedings of the National Academy of Sciences 110:12149-12154.

Rosegrant, M. W., and S. A. Cline. 2003. "Global Food Security: Challenges and Policies.” Science 302:1917-1919.

Savelle, R., and L. J. O'Neal. 2017. Food Security and Obesity. FCS3342. Gainesville: University of Florida Institute of Food and Agricultural Sciences. https://edis.ifas.ufl.edu/ fy 1473

Seto, K. C., J. S. Golden, M. Alberti, and B. L. Turner. 2017. "Sustainability in an Urbanizing Planet." Proceedings of the National Academy of Sciences 114:8935-8938. 